\title{
The feasibility of hybrid solar-biomass power plants in India
}

\author{
J. D. Nixon ${ }^{\mathrm{a}}$, P. K. Dey ${ }^{\mathrm{b}}$ and P. A. Davies ${ }^{\mathrm{a}}$ \\ ${ }^{\text {a }}$ Sustainable Environment Research Group, School of Engineering and Applied Science \\ Aston University, Aston Triangle, Birmingham, B4 7ET, UK \\ ${ }^{\mathrm{b}}$ Aston Business School, Aston University, Aston Triangle, Birmingham, B4 7ET, UK \\ *corresponding author, e-mail: p.a.davies@aston.ac.uk, Tel +44 1212043724
}

\begin{abstract}
We assess the feasibility of hybrid solar-biomass power plants for use in India in various applications including tri-generation, electricity generation and process heat. To cover this breadth of scenarios we analyse, with the help of simulation models, case studies with peak thermal capacities ranging from 2-10 MW. Evaluations are made against technical, financial and environmental criteria. Suitable solar multiples, based on the trade-offs among the various criteria, range from 1-2.5. Compared to conventional energy sources, levelised energy costs are high - but competitive in comparison to other renewables such as photovoltaic and wind. Long payback periods for hybrid plants mean that they cannot compete directly with biomass-only systems. However, a 1.2-3.2 times increase in feedstock price will result in hybrid systems becoming cost competitive. Furthermore, in comparison to biomass-only, hybrid operation saves up to $29 \%$ biomass and land with an 8.3-24.8 \$/GJ/a and 1.8-5.2 $\mathrm{k} / \mathrm{kWh}$ increase in cost per exergy loss and levelised energy cost. Hybrid plants will become an increasingly attractive option as the cost of solar thermal falls and feedstock, fossil fuel and land prices continue to rise. In the foreseeable future, solar will continue to rely on subsidies and it is recommended to subsidise preferentially tri-generation plants.
\end{abstract}

Keywords:

solar thermal; tri-generation; linear Fresnel reflector (LFR); energy policy; exergy. 
Fluid temperature rise $(\mathrm{K})$

Area of receiver $\left(\mathrm{m}^{2}\right)$

Aperture area of solar field $\left(\mathrm{m}^{2}\right)$

Biomass saved (tonnes/a)

Cost of biomass feedstock (\$/a)

Cost of boiler $(\$)$

Capital cost $(\$)$

Cost of chiller $(\$)$

Cost of electricity (\$)

Annual insurance costs (\$/a)

Cost of land (\$)

Operations and maintenance cost (\$/a)

Cost of rest of power block (\$)

Cost per exergy loss

Specific heat capacity of ice $(\mathrm{kJ} / \mathrm{kgK})$

Specific heat capacity of steam $(\mathrm{kJ} / \mathrm{kgK})$

Specific heat capacity of water $(\mathrm{kJ} / \mathrm{kgK})$

Cost of solar field (\$)

Annual replacement costs $(\$ / a)$

Cost of employees (\$/a)

Cost of turbine (\$)

Cost of water (\$/a)

Direct normal irradiance $\left(\mathrm{W} / \mathrm{m}^{2}\right)$

Electricity produced $\left(\mathrm{MWh}_{\mathrm{e}} / \mathrm{a}\right)$

Percentage of electricity from biomass input

Percentage of electricity from solar input

Auxiliary electrical requirement $\left(\mathrm{MWh}_{\mathrm{e}} / \mathrm{a}\right)$

Value of saleable electricity (\$/a)

Exergy received

Exergy delivered

Collector efficiency factor (-)

Collector flow factor (-)

Fixed charge rate (-)

Number of employees for power block (-)

Heat removal factor (-)

Solar share - Fraction of total useful energy from solar input (\%)

Number of employees for solar field (-)

Generator efficiency (\%)

Incidence angle modifier (-)

Turbine isentropic efficiency (\%)

Value of Ice (\$/a)

Interest rate on debt (\%)

Length of receiver pipe (m)

Levelised cost of electricity ( $₫ / \mathrm{kWh})$

Levelised energy cost ( $\varnothing / \mathrm{kWh})$

Latent heat of evaporation for water $(\mathrm{kJ} / \mathrm{kg})$

Latent heat of fusion for water $(\mathrm{kJ} / \mathrm{kg})$

Lower heating value $(\mathrm{kJ} / \mathrm{kg})$

Land saved (ha)

Mass of biomass (tonnes) 
Mass flow in solar field $(\mathrm{kg} / \mathrm{s})$

$\mathrm{m}_{\text {turb }}$

$\mathrm{M}_{\text {water }}$

$\mathrm{P}_{\mathrm{ar}}$

$\mathrm{P}_{\text {exit }}$

$\mathrm{P}_{\text {inlet }}$

$\mathrm{PP}_{\text {cap }}$

$\mathrm{PP}_{\text {sol }}$

$\mathrm{P}_{\mathrm{wr}}$

Qboiler

$\mathrm{Q}_{\mathrm{e}}$

$\mathrm{Q}_{\text {in }}{ }^{*}$

Q reject,h

Q reject,1

$\mathrm{Q}_{\mathrm{u}}$

$\mathrm{Q}^{\text {year }}$

$\mathrm{S}$

$\mathrm{T}_{1}$

$\mathrm{T}_{2}$

$\mathrm{Ta}$

$\mathrm{TA}_{\mathrm{SF}}$

$\mathrm{T}_{\text {exit }}$

$\mathrm{T}_{\mathrm{s}}$

$\mathrm{T}_{\text {ice }}$

$\mathrm{T}_{\text {in }}$

TMY

$\mathrm{U}_{\mathrm{L}}$

$\mathrm{U}_{\mathrm{o}}$

$\mathrm{W}_{\text {net }}$

$\mathrm{W}_{\text {turb }}$

$\eta_{(\theta=0)}$

$\eta_{\mathrm{I}}$

$\eta_{\mathrm{II}}$

Subscripts

$c$

b

hc

Mass flow in turbine $(\mathrm{kg} / \mathrm{s})$

Mass of water (tonnes)

Profits after capital repayments (\$/a)

Turbine exit pressure (bar)

Turbine inlet pressure (bar)

Capital cost payback period (years)

Solar investment payback period (years)

Profits with capital repayments (\$/a)

Useful energy from boiler (GJ/a)

Heat absorbed by chiller (GJ/a)

Solar radiation rate of on solar field (GJ/a)

High grade reject heat from solar field (GJ/a)

Low grade reject heat from chiller $(\mathrm{GJ} / \mathrm{a})$

Useful energy gained from solar field (GJ/a)

Annual solar insolation $\left(\mathrm{GJ} / \mathrm{m}^{2} / \mathrm{a}\right)$

Absorbed solar radiation $\left(\mathrm{W} / \mathrm{m}^{2}\right)$

Turbine inlet temperature $\left({ }^{\circ} \mathrm{C}\right)$

Turbine exit temperature $\left({ }^{\circ} \mathrm{C}\right)$

Ambient temperature (K)

Total land usage of solar field (K)

Exit temperature from solar field (K)

Heat transfer fluid temperature (steam) $(\mathrm{K})$

Temperature of ice $(\mathrm{K})$

Inlet temperature to solar field (K)

Typical meteorological year (-)

Heat loss coefficient $\left(\mathrm{W} / \mathrm{m}^{2} . \mathrm{K}\right)$

Overall heat loss coefficient $\left(\mathrm{W} / \mathrm{m}^{2} . \mathrm{K}\right)$

Net work of plant

Work at turbine $(\mathrm{GJ} / \mathrm{a})$

Optical efficiency at normal incidence (\%)

Energy efficiency

Exergetic efficiency

Collector (solar thermal field)

Boiler (biomass)

Heat cycle

os

Overall system 


\section{Introduction}

India receives a high level of Direct Normal Irradiance (DNI), $4-7 \mathrm{kWh} / \mathrm{m}^{2}$ per day. Thus, there is a vast potential for decentralised solar energy applications using Concentrating Solar thermal Power (CSP). However, CSP technologies are currently expensive and the uptake in India has been slow. The Jawaharlal Nehru National Solar Mission was established in 2010 and outlined support for solar energy applications to encourage market penetration of gridconnected and decentralized off-grid applications, to provide energy services in India $[1,2]$. One CSP technology of particular interest is the Linear Fresnel Reflector (LFR), due to its comparatively simple and inexpensive design. The LFR uses multiple rows of low profile mirrors to focus solar radiation onto a fixed target pipe to generate steam directly. Such Direct Steam Generation (DSG) is an alternative to the more commonly employed Heat Transfer Fluids (HTFs) - synthetic oil and molten salt - and has the potential to increase CSP plant efficiency and reduce costs [3]. However, thermal energy is difficult to store in DSG systems [3-5]. Auxiliary fossil/biomass boilers can therefore play a role in achieving temperature and load stability in LFR power plants.

The potential for biomass boilers in India is vast with over 370 million tonnes of biomass being produced every year [6]. Biomass is available from agricultural wastes, direct harvesting and as a by-product from industries such as rice mills, sugar mills and saw mills. However, due to problems with infrastructure and the seasonal variability of biomass in India, consumers are struggling to obtain a consistent fuel supply. Furthermore, while biomass is still competitive, prices have increased considerably in recent years $[7,8]$.

Hybridisation of solar thermal with biomass combines two energy sources that complement each other, both seasonally and diurnally, to overcome their individual drawbacks. During the day the sun's rays can be harnessed by solar collectors and biomass feedstock can be burnt as a supplementary fuel to achieve constant base load operation. CSP plants benefit from hybridisation or effective energy storage due to the variable nature of solar energy, particularly in India's monsoon season. Constant base load or full load plants are typically implemented as plant efficiency is maximised and unit cost of energy is minimised. However, solar energy could be used to increase plant output during the day. In comparison to a biomass-only system, solar hybridisation reduces biomass demand, thus improving energy security and decreasing land required for farming and storage.

Hybrid solar systems have been investigated before. Kaushika et al. [9] studied a hybridised distillery waste-based co-generation plant with solar energy for India, with the bio-gas demand in relation to the amount of solar heat generated considered. Popov [10] modelled a Fresnel collector system for boiler preheating in a Rankine regenerative cycle for repowering fossil fuel power plants using Thermoflow's THERMOFLEX library [10]. Lerchenmüller et al. [11] at the Fraunhofer Institute evaluated various aspects of hybridising the LFR with biomass or gas co-firing for different solar shares, i.e. the percentage of electricity generated from solar energy as determined by the aperture area of the solar field. They calculated thermal and electrical outputs for constant full load operation using ColSim, an in-house 
simulation tool. Key economic indicators from the study included the Levelised Cost of Electricity (LCOE) and average annual profit after interest rate repayments. The LCOE is the payment a plant must receive for each unit of electricity in order to meet operational costs.

Bermejo et al. [12] tested an LFR solar-gas cooling plant to identify design improvements that could be made on solar collector size, operation control and coupling to chiller. Cot et al. [13] presented the concept of 'Termosolar Borges' a hybrid CSP plant that will operate with a gas boiler during the day to respond to fast transients and a biomass boiler at night. Termosolar Borges will be the world's first hybrid CSP plant, and is expected to commence selling electricity to the Spanish grid in January 2013. A small scale demonstration project aiming for completion in June 2012 is TRESERT in Phitsanulok, Thailand. This is a hybrid power plant for tri-generation (electricity, heat and refrigeration) [14].

Several other studies have evaluated and optimised CSP power plants based on the criterion of LCOE [15, 16]. Considering LCOE and fossil-fuel demand, Montes et al. [3] assessed plant performance of a DSG hybrid solar thermal-fossil fuel plant as a function of Solar Multiple (SM), which is defined as the ratio of the solar field mirror aperture area to the size of the field aperture that produces sufficient energy, including thermal and optical losses, to drive a prime mover at its rated capacity at a design irradiance value. The SM therefore provides a measure of hybridisation. Frebourg et al. [17] studied the feasibility of a small scale grid connected hybrid solar-biomass power system in Thailand. Beerbaum et al. [18] have also estimated the LCOE for large CSP power plants in India.

Energy and exergy analyses (or first law and second law analyses) have been widely adopted to provide a comprehensive assessment of thermodynamic cycles. Exergy is particularly useful in assessing power generation systems to establish the maximum work potential and the true magnitude of losses and their locations. Bhattacharya et al. [19] performed an energy and exergy analysis of a hybrid gas-biomass system, and determined the optimum degree of supplementary firing to maximise exergetic efficiencies and the major sources of exergy losses in the cycle. Vidal et al. [20] established the exergy loss in each component of a combined power and refrigeration cycle, finding the highest irreversibilities to occur in the heat exchanger. Singh et al. [21] performed an exergy analysis of a solar thermal power station finding the maximum energy loss to occur at the condenser, while the exergy analysis determined that the maximum losses occurred in the solar thermal field.

Exergetic analyses have also been combined with economic studies as exergy is the part of energy that is useful to society and therefore has economic value [22, 23]. Such exergoeconomic analyses are typically used for design optimisation, assessing feasibility, and comparing system operating conditions and technologies, by evaluating the cost associated with the exergy loss in system components [24]. Rosen and Dincer [25] identified the correlation of total or internal exergy loss and capital cost leading to an overall optimum design for coal, oil and nuclear power stations. Kaushik et al. [26] performed an exergoeconomic evaluation of a solar thermal power plant, identifying the system components that would benefit the most from an increased capital cost to reduce exergy loss. 
Hepbasli [27] provides a comprehensive review of exergetic studies of sustainable energy systems.

Hybrid plant studies in the literature have been primarily focused on the LCOE with electricity as the sole output. As indicated, the concept of exergy has been widely adopted in the power generation sector, but no assessment of hybrid solar-biomass systems has been made. A range of hybrid solar-biomass applications and the resulting drawbacks and benefits for varying levels of hybridisation have not been thoroughly investigated. In addition to generating electricity, hybrid systems can provide heat for industrial processes. A promising hybrid application in India is a tri-generation plant, producing electricity, ice and reject heat, through the use of an LFR solar field, biomass boiler, steam turbine and absorption chiller (Figure 1). Many industries have a large demand for steam and, in food-processing facilities, requirements for thermal energy and ice may exceed that for electricity. India currently loses $20-40 \%$ of its vegetable and fruit food production before it reaches the consumer due to high temperatures and coinciding harvests [28]. There is therefore a need for ice in short and long term food preservation; and in certain areas of India this extends to fisheries and chemical plants.

The aim of this paper is to assess the feasibility and prospects of hybrid solar-biomass power plants for various applications in India. Instead of optimising purely based on LCOE, a range of applications will be considered including base and peak load demands for tri-generation, electricity generation and process heat. The following specific research questions will be addressed:

Q1. What is the appropriate solar multiple for a hybrid plant?

Q2. How do the levelised energy costs of alternative hybrid applications compare to other energy sources, renewable and conventional?

Q3. How does the hybrid plant compare to a biomass-only plant?

Q4. Which is the most feasible application for a hybrid solar-biomass power plant; trigeneration, electricity generation or industrial process heat?

The answers will enable us to evaluate hybrid plants and to recommend on the best applications of such plants. This will have implications for policymakers interested in incentivising biomass and solar energy and for plant designers and investors.

The methodology of this paper is based on five case studies chosen to cover a range of scenarios for hybrid LFR-biomass power plants (Table 1). The data for the case studies has been gathered from the field or from the background literature. A simulation model has been developed in TRNSYS ${ }^{\circledR}$ [29] for application to the case studies and this model will be described in detail. Each case study will be analysed with variable sizes of solar field, as represented by the solar multiple. Evaluations and comparisons will thus be made against technical, financial and environmental criteria, to provide answers to the research questions above. Technical performance is evaluated through an energy and exergy analysis. Financial assessment is made against the costs per exergy losses, levelised energy costs and payback periods. Environmental impact is judged in terms of biomass and land saving. 


\section{Evaluation criteria and assumptions}

The evaluation will require several criteria as used by other authors $[3,11-13,15-18,21,26$, 30]. These criteria fall into three categories:

1. Technical: energy efficiency $\left(\eta_{\mathrm{I}}\right)$ and exergetic efficiency $\left(\eta_{\mathrm{II}}\right)$.

2. Financial: cost per exergy loss $\left(\mathrm{C}_{\text {pel }}\right)$ Levelised Cost of Electricity (LCOE), Levelised Energy Cost (LEC), Payback Period on total capital cost $\left(\mathrm{PP}_{\text {cap }}\right)$ and Payback Period on cost of solar field $\left(\mathrm{PP}_{\mathrm{sol}}\right)$.

3. Environmental: mass of biomass saved ( $\left.\mathrm{B}_{\text {saved }}\right)$ and resulting land saved $\left(\mathrm{L}_{\mathrm{saved}}\right)$.

The assumptions and equations used for calculating these criteria will be defined.

\subsection{Technical}

The energy efficiencies ( $1^{\text {st }}$ law efficiency, $\left.\eta_{I}\right)$ and exergetic efficiencies $\left(2^{\text {nd }}\right.$ law efficiency, $\left.\eta_{I I}\right)$ of the hybrid plants' components (solar field, biomass boiler, heat cycle and overall system) are studied to provide a quantitative and qualitative assessment of the energy conversion process at each stage in the system.

The hybrid plant's overall system energy efficiency is given by,

$\eta_{I, o s}=\frac{W_{n e t}}{\frac{Q_{\text {boiler }}}{\eta_{I, b}}+\frac{Q_{u}}{\eta_{I, c}}}$

The net work, $W_{\text {net }}$, is a result of the annual work at the turbine, $W_{\text {turb }}$, and heat absorbed by the chiller, $Q_{e}$. The auxiliary load of the plant is assumed to be 1.25 times the auxiliary electrical requirement, $E_{\text {el, aux }}$.

$W_{\text {net }}=W_{\text {turb }}+Q_{e}-\left(E_{\text {el,aux }} \cdot 1.25\right)$

The useful energies transferred to the steam from the biomass boiler and solar thermal field are expressed as $Q_{b o i l e r}$ and $Q_{u}$ respectively. The boiler efficiency, $\eta_{I, b}$, which varies for part loads, can be determined from the following equation:

$\eta_{I, b}=\frac{Q_{b o i l e r}}{M_{\text {bio }} \cdot L H V}$

The mass of the biomass feedstock consumed is given by $M_{b i o}$. The Lower Heating Value (LHV) for fuels specifies the amount of energy released per mass of fuel during combustion.

The annual solar radiation rate on a solar thermal field, $Q_{i n}{ }^{*}(\mathrm{GJ} / \mathrm{a})$, is calculated from the solar insolation, $Q^{\text {year }}\left(\mathrm{GJ} / \mathrm{m}^{2} / \mathrm{a}\right)$, and the field's aperture area, $A_{S F}$ : 
$Q_{i n}{ }^{*}=Q^{\text {year }} \cdot A_{S F}$

Thus, the energy efficiency of the solar field, $\eta_{I, c}$, is given by $\mathrm{Q}_{\mathrm{u}} / \mathrm{Q}_{\text {in }}$.

Each case study is evaluated to determine the exergy received and delivered by each system component. The exergy received, $E x_{c}$, and exergy delivered, $E x u_{c}$, by the solar thermal field are given by,

$E x_{c}=\left(Q_{i n}\right)\left[1-\frac{T_{a}}{T_{\text {solar }}}\right]$

$E x u_{c}=Q_{u}\left[1-\frac{T_{a}}{T_{s}}\right]$

where $T_{\text {solar }}$ is the apparent black body temperature of the sun $(5600 \mathrm{~K}), T_{s}$ is the temperature of steam available to the heat cycle and $\underline{T_{a}}$ is the ambient temperature.

The exergy received, $E x_{b}$, and delivered, $E x u_{b}$, by the biomass boiler are determined from,

$E x_{b}=e^{C H} \cdot M_{b i o}$

$\operatorname{Exu}_{b}=Q_{\text {boiler }}\left[1-\frac{T_{a}}{T_{s}}\right]$

where $e^{C H}$ is the chemical exergy of dry biomass; estimates for a variety of feedstocks are given in [31].

The exergy received by the heat cycle, $E x_{h c}$, is the sum of the exergy delivered by the collector and boiler. The exergy delivered by the heat cycle and overall system are calculated from the net work. The exergetic efficiencies of the solar field, $\eta_{I I, c}$, boiler, $\eta_{I I, b}$, heat cycle, $\eta_{I I, h c}$, and overall system, $\eta_{I I, o s}$, are calculated from the following equations.

$$
\begin{aligned}
& \eta_{I I, c}=\frac{E x u_{c}}{E x_{c}} \\
& \eta_{I I, b}=\frac{E x u_{b}}{E x_{b}} \\
& \eta_{I I, h c}=\frac{W_{n e t}}{E x u_{c}+E x u_{b}} \\
& \eta_{I I, o s}=\frac{W_{n e t}}{E x_{c}+E x_{b}}
\end{aligned}
$$


The main outputs from the plant include the electricity produced, $E_{e l}$, mass of ice, $M_{i c e}$, and low and high grade reject heat. Surplus heat from the solar thermal field is categorised as high grade reject heat, $Q_{\text {reject, },}$, as temperatures will be the region of $300{ }^{\circ} \mathrm{C}$. Low grade reject heat, $Q_{\text {reject, },}$, temperatures less than $100{ }^{\circ} \mathrm{C}$, will be produced from the chiller.

The total mass of ice produced is determined from the following [32],

$Q_{e}=M_{\text {water }} C_{p w} T_{a}+M_{i c e} L_{f w}+M_{i c e} C_{p i} T_{i c e}$

where $C_{p w}$ and $C_{p i}$ are the specific heat capacity of water and ice, $L_{f w}$ is the latent heat of fusion for water, and $T_{a}$ and $T_{i c e}$ are the ambient temperature and desired ice temperature.

\subsection{Financial}

The capital cost per exergy loss, $C_{p e l}$, for each plant component (solar field, $C_{p e l, c}$, boiler, $C_{p e l, b}$, heat cycle, $C_{p e l, h c}$, and overall system, $\left.C_{p e l, o s}\right)$ is evaluated from:

$$
\begin{aligned}
& C_{p e l, c}=\frac{A_{S F} \cdot c_{S f}+c_{\text {land }} \cdot T A_{S F}}{E x_{c}-E x u_{c}} \\
& C_{p e l, b}=\frac{c_{\text {boiler }}+c_{\text {bio }}}{E x_{b}-E x u_{b}} \\
& C_{p e l, h c}=\frac{c_{t u r b}+c_{c h i l l}+c_{p b}}{E x_{h c}-W_{n e t}} \\
& C_{p e l, o s}=\frac{C_{\text {capital }}}{E x_{c}+E x_{b}-W_{\text {net }}}
\end{aligned}
$$

The capital cost of the plant, $C_{\text {capital }}$, and cost of operations and maintenance, $C_{O \& M}$, for the hybrid plant are calculated from:

$$
\begin{aligned}
& C_{\text {capital }}=\left(A_{S F} \cdot c_{S f}+c_{\text {land }} \cdot T A_{S F}+c_{\text {boiler }}+c_{\text {turb }}+c_{\text {chill }}+c_{p b}\right) \\
& C_{\text {O\&M }}=\left(f_{\text {SFstaff }} \cdot T A_{S F}+f_{\text {PBstaff }}\right) \cdot c_{\text {staff }}+c_{\text {ins }}+c_{\text {water }}+c_{\text {spare }}+c_{\text {bio }}
\end{aligned}
$$

It has been estimated that an LFR solar field, based on aperture area, must cost below 281 $\$ / \mathrm{m}^{2}\left(216 € / \mathrm{m}^{2}\right)$ to be competitive with other CSP technologies [33]. Typical costs for an LFR system are around $235 \$ / \mathrm{m}^{2}$ [34]. The Solar Mission has proposed a 30\% capital cost subsidy for solar energy technologies implemented in India, therefore, a value of $165 \$ / \mathrm{m}^{2}$ is assumed for the cost of the solar field, $c_{s f}$. In addition, the Solar Mission outlined the availability of soft loans at a 5\% interest rate for solar energy projects, and a $60 \%$ capital cost subsidy for un-electrified rural regions of India [1]. Therefore, depending upon the hybrid plant scenario, these financial incentives may or may not be considered. Land usage for the 
solar field is assumed to be three times that of its aperture area. The cost of land procurement and preparation, average salary of a medium skilled employee and value of ice are taken to be $20 \$ / \mathrm{m}^{2}, \$ 2000$ per annum and $40 \$ /$ tonne respectively, which are values gathered by the authors during site visits to companies in Gujarat. The cost of the biomass boiler, $c_{b o i l e r}$, is assumed to be $\$ 54,000$ per tonne of steam produced per hour. Depending upon the amount of ice produced per hour the cost of the chiller, $c_{\text {chill, }}$, is taken to be $\$ 25,000$ per tonne of ice produced per hour [35]. The cost of the turbine, $c_{\text {turb }}$, is highly variable and depends upon the steam turbine selected. The additional cost for the rest of the power block, $c_{p b}$, is assumed to be $40 \$ \mathrm{MWh}_{\mathrm{e}}$. Other operational costs include the biomass, $c_{b i o}$, which will depend on feedstock type and site location. The number of staff required for the solar field and rest of the plant is assumed to be 2 persons/hectare and 10 employees respectively (control, hauling ice, repairs, security, etc.) The cost of the water consumption is taken to be $1.73 \$ / \mathrm{MWh}$ [30]. And the annual part replacement and plant insurance cost are both assumed to be $1 \%$ of the total capital cost. The LCOE is used determine the cost of the electricity produced. The Levelised Energy Cost (LEC) is used to determine the unit cost of other energy outputs, i.e. cooling effect and electrical generation.

LCOE $=\frac{\left(C_{\text {capital }}-c_{\text {chiller }}\right) \cdot F C R+C_{O \& M}}{E_{e l}-E_{e l, a u x}}$

$L E C=\frac{C_{\text {capital }} \cdot F C R+C_{O \& M}}{Q_{t u r b}+Q_{e}}$

where the Fixed Charge Rate (FCR) can be determined by the real debt interest, $k_{d}$, over an $n$ number of years.

$F C R=\frac{k_{d} \cdot\left(1+k_{d}\right)^{n}}{\left(1+k_{d}\right)^{n}-1}$

In this study an FCR is determined from the rate of return to repay the capital cost of the plant over a 20 year period (e.g. for a $5 \%$ interest rate loan, $\mathrm{FCR}=8 \%$ ). The cash flow earned by the plant is determined from the value of ice, $I_{v a l}$, and electricity, $E_{\text {el, val }}$. Electricity generated from the solar and biomass input is assumed to be saleable at a different fixed tariff rate. Thus, the percentage of electricity produced from solar, $E_{e l, \% \text { sol }}$, and biomass, $E_{e l, \% b i o}$, are calculated to determine a total electricity value. With tariff incentives for electricity generation from solar and biomass being dependent on a number of factors - state, capacity, year, etc. - a fixed value of $19 \phi / \mathrm{kWh}$ is taken for solar, as solar projects commissioned after $31^{\text {st }}$ December 2009 were eligible for this rate in India [37]. The assumption is made that electricity generated from biomass is sold, and electricity is bought, at an industry rate of 12 $\phi / \mathrm{kWh}$. The fraction of the total useful energy from the solar input is termed the solar share, $F S$.

$E_{e l, v a l}=19 \cdot E_{e l, \% \text { sol }} \cdot\left(E_{e l}-E_{e l, a u x}\right)+12 \cdot E_{e l, \% b i o} \cdot\left(E_{e l}-E_{e l, a u x}\right)$ 
The annual profit of the plant after FCR repayments, $P_{a r}$, and with FCR repayments (e.g. loans), $P_{w r}$, is determined from:

$P_{a r}=I_{v a l}+E_{e l, v a l}-C_{o \& M}$

$P_{w r}=I_{v a l}+E_{\text {el, val }}-C_{\text {o\&M }}-C_{\text {capital }} \cdot F C R$

To investigate the benefit of a hybrid plant in comparison to a biomass-only plant it is useful to determine the payback period for the additional investment in solar energy, $P P_{\text {sol }}$, which is specified by the capital cost and profit of a hybrid plant for a given solar multiple $(\mathrm{SM}=m)$ and a biomass-only plant $(\mathrm{SM}=0)$ :

$P P_{\text {sol }}=\frac{C_{\text {capital }}\left(P_{w r}(S M=0)-P_{w r}(S M=m)\right)}{P_{a r}(S M=m)-P_{a r}(S M=0)}+n$

The payback period or breakeven time for the overall plant's capital cost, $P P_{c a p}$, is also included as it is a key indicator for investors of whether a project is financially feasible. Tax rates and other financial incentives such as carbon credits are not considered. All monetary values in this paper are presented in US dollars, converted at an exchange rate of 1 Indian Rupee (INR) $=0.02$ US Dollar (USD).

\subsection{Environmental}

The key environmental factors considered are the amount of biomass and land saved, $B_{\text {saved }}$ and $L_{\text {saved }}$, relative to biomass-only operation. The land usage is calculated based on a crop yield assumption of 13 tonnes per hectare annum [38].

\section{Simulation model of hybrid plant}

Several software packages with the capability to enable users to model solar thermal and renewable energy based power plants are available. Examples include: Thermoflex, Ebsilon, IPSEpro, TRNSYS, SAM, Greenius and ColSim. For the purposes of this study a hybrid LFR-biomass power plant model to determine the criteria values has been developed in TRNSYS, a validated TRaNsient SYstem Simulation software tool. It is a graphical software environment, typically used to model the performance of thermal and electrical energy generating systems, and has been previously applied in the field of CSP [39, 40]. Each component forming the hybrid plant model is now described. Mathematical models and assumptions used are explicitly provided.

\subsection{Biomass boiler}

A TRNSYS steam boiler component developed by Liebecq at the Solar Energy Laboratory is used to model the biomass boiler [41]. The model enables information on the composition of the fuel to be specified as a main parameter. Published fuel compositions for a variety of agricultural wastes are reported in the literature [42-45]. For a given steam demand, temperature and pressure, the boiler efficiency, flue gas temperature and biomass feed rate are calculated. Losses due to flue gas, blowdown, ash removal, radiation and convection are 
also considered. The boiler is considered as a counter flow heat exchanger with the flue gas exchanging heat to the supply water through an economizer, evaporator and superheater section.

\subsection{Solar field operation}

To model the solar field a custom component has been developed in TRNSYS. The hourly performance of the solar field is modelled based on the typical parameters for an LFR: Concentration ratio, $C$, Incident Angle Modifier, IAM, optical efficiency at normal incidence, $\eta_{(\theta=0)}$ and heat loss coefficient, $U_{L}[46]$.

The solar field's flow characteristics are modelled using a series of equations for the collector efficiency factor, $F$ ', collector flow factor, $F^{\prime}$,' and heat removal factor, $F_{R}$, to determine the HTF mass flow rate, $m_{\text {sol }}$, to achieve a desired exit temperature $[47,48]$.

$F^{\prime}=\frac{U_{0}}{U_{L}}$

$F^{\prime \prime}=\frac{m_{s o l} C_{p}}{A_{r} U_{L} F^{\prime}}\left[1-\exp -\left(\frac{A_{r} U_{L} F^{\prime}}{m_{s o l} C_{p}}\right)\right]$

$F_{R}=F^{\prime \prime} x F^{\prime}$

where $A_{r}$ is the receiver's absorber area and $C_{p}$ is the specific heat capacity of the HTF. The useful heat gain, $Q_{u}$, is determined from:

$Q_{U}=F_{R} A_{S F}\left[S-\frac{A_{r}}{A_{S F}} U_{L}\left(T_{i n}-T_{a}\right)\right]$

where,

$S=D N I \cdot \eta_{(\theta=0)} \cdot I A M$

and $T_{i n}$ and $T_{a}$ are the receiver inlet temperature and ambient temperature. The fluid temperature rise, $\Delta T$, for a given mass flow rate is calculated from:

$\Delta T=\frac{Q_{u}}{m_{s o l} C_{p}}$

The receiver sections which act as a pre-heater, evaporator and boiler have to be treated individually. Thus, for a given inlet temperature the mass flow can be determined to achieve a specified exit temperature, $T_{\text {exit }}$.

$m_{\text {sol }}=\frac{Q_{u}}{\left[C_{p w}\left(100-T_{i n}\right)+L_{e w}+C_{p s}\left(T_{\text {exit }}-100\right)\right]}$ 
Iterative calculations are required as $Q_{u}, m_{s o l}$ and $U_{L}$ are dependent on each other. The solar field aperture area required to provide enough useful heat gain to achieve the maximum thermal requirement (mass flow and temperature) at the turbine, for peak cosine-adjusted DNI in a Typical Meteorological Year (TMY), i.e. S.M = 1, can then be determined. For SM $>1$ the flow rate from the solar field can be too high to be utilised by the turbine, thus excess flow is siphoned off. At night, flow bypasses the solar field. The field pipe losses are not considered.

\subsection{Refrigeration plant}

A single effect absorption chiller within the TRNSYS component files is used to model the heat absorbed from a chilled flow stream, heat rejected to a cooling flow stream and auxiliary electrical load. The chiller is assumed to operate with a constant COP of 0.5 and a calcium chloride $\mathrm{CaCl}_{2}$ brine solution with a specific heat capacity of $3.2 \mathrm{~kJ} / \mathrm{kg} \mathrm{K}$ for the chilled stream [49]. The aqueous $\mathrm{CaCl}_{2}$ solution is chosen as it enables temperatures below $0{ }^{\circ} \mathrm{C}$ to be obtained in the chiller. An additional component has been modelled to control the chilled stream to match the varying hot water flow rates $\left(193-220^{\circ} \mathrm{C}\right)$, so that a constant hot water exit temperature of $50{ }^{\circ} \mathrm{C}$ is achieved. Heat was rejected via the cooling stream entering at the ambient with a constant flow rate of $2.5 \mathrm{~kg} / \mathrm{s}$. The cooling stream flow rate could also be controlled to maintain a constant exit temperature for another process heat application; however, this has not been considered. The desired chilled stream exit temperature from the chiller is specified as $-20{ }^{\circ} \mathrm{C}$. It is assumed that ice is produced in a perfectly insulated brine tank. Therefore, the energy absorbed by the brine to chill water-ice from the ambient to $-5{ }^{\circ} \mathrm{C}$ is equivalent to the energy absorbed from the brine in the chiller.

\subsection{Turbine selection}

The steam turbine has been modelled using data gathered on two back pressure turbines (BT4 , and SST-060) and assumptions made for a condensing turbine. The BT-4 operates with an isentropic efficiency of $45 \%$. The generator efficiency ranges from $82-89 \%$. The SST-060 has an isentropic efficiency of around 39-53\% with a generator efficiency of 79-92\%. Monetary values have also been obtained, the capital cost of the BT-4 and SST-060 is $\$ 120,000$ and $\$ 660,000$ respectively. The operational range in terms of full and part load flow rates, mechanical outputs, pressures, temperatures, and efficiencies are given in Table 2. A cost of $\$ 800,000$ is assumed for the condensing turbine.

\section{Case studies}

In this section, the key features of the five hybrid plant case studies are presented (as summarised in Table 1). Each case includes details on plant application, site location, sizing, operational parameters and assumptions. Results for the evaluation criteria defined in section 2 are plotted against SM.

\subsection{Case study 1 - Gujarat pilot plant}

The Gujarat hybrid plant is a pilot system to be implemented in Vapi, India. The project is part funded by research grants and therefore has a low FCR of 5\%. The plant will provide 
electricity to the grid, and ice to nearby fisheries and chemical plants. In the future, surplus heat will be used for additional process steam applications. The plant will operate with a 3 tonne boiler and BT-4 steam turbine. Rice husk feedstock, with an LHV of $14 \mathrm{MJ} / \mathrm{kg}$, will be sourced at a cost of $40 \$ /$ tonne.

The Gujarat plant is modelled using the following conditions. At the biomass boiler's full load, steam exits at $280^{\circ} \mathrm{C}, 8.5 \mathrm{bar}$ and $0.83 \mathrm{~kg} / \mathrm{s}$, thus providing the part load thermal requirement of the turbine. Additional steam is sent to the turbine from the solar field until the mass flow reaches $0.415 \mathrm{~kg} / \mathrm{s}$; at this state the biomass boiler is switched to part load (i.e. the two flow streams are combined to achieve the part load of the turbine). If the solar field's mass flow reaches $0.83 \mathrm{~kg} / \mathrm{s}$ the boiler is shut down and hot banked; the fuel and energy requirement is not included. For an $\mathrm{SM}>1$, the steam mass flow rate from the field is limited to a maximum of $1.66 \mathrm{~kg} / \mathrm{s}$, hence, additional flow is siphoned off. Exhaust steam from the turbine is sent to the chiller where it exits at $50^{\circ} \mathrm{C}$. The TMY for the nearest weather station, Rajkot, is used. For the Gujarat plant a solar multiple of 1 requires a solar field aperture area of $9350 \mathrm{~m}^{2}$. Results for the Gujarat pilot plant are shown in Figure 2a-d.

\subsection{Case studies 2, 3 and 4 - College-peak load, base load and electricity only}

An educational institution in Tamilnadu is aiming to improve their sustainability by combining solar and biomass energy to provide electricity and cooling, or electricity only, to their campus buildings. In addition, they are also interested in designing a system that best meets their demand. Three case studies are therefore modelled.

College-peak load and base load (cases 2 and 3) are modelled with a STT-060 turbine (requiring steam at $300{ }^{\circ} \mathrm{C}$ and 8.5 bar), a biomass boiler running on coconut shells and a chiller. For case 2 the mass flow from the solar field and biomass boiler is controlled as presented for case 1, i.e. peak demand during the day. For this case a 4 tonne boiler with a full load steam rate of $1.18 \mathrm{~kg} / \mathrm{s}$ is chosen. Case 3 is controlled so that a constant base load is achieved. For this case a larger 10.8 tonne boiler (steam rate equal to $3 \mathrm{~kg} / \mathrm{s}$ ) is modelled. The boiler is assumed to complement the solar input with an ideal response in the range of 40$100 \%$ of its peak thermal requirement. Thus, steam at a flow rate of up to $1.8 \mathrm{~kg} / \mathrm{s}$ from the solar field is added to the steam flow from the biomass boiler. Surplus flow is generated from the solar field for flow rates greater than $1.8 \mathrm{~kg} / \mathrm{s}$. However, if the solar field achieves a steam flow of $3 \mathrm{~kg} / \mathrm{s}$ the biomass boiler is turned off and hot banked. Surplus flow is therefore produced for flow rates greater than $3 \mathrm{~kg} / \mathrm{s}$. For both cases 2 and 3, the assumption is made that electricity and ice produced is sold at the fixed tariff rates outlined in section 2.2. In reality, the plant may provide electricity and cooling purely as amenities to the campus buildings. The key results for the College-peak and -base load case studies are plotted in Figures $3 \mathrm{a}-\mathrm{d}$ and $4 \mathrm{a}-\mathrm{d}$.

College-electricity (case 4 ) is modelled similarly to case 3, except that a condensing turbine is used rather than a back pressure turbine-chiller combination, (see Figure 5a-d). In all cases the weather data from the Coimbatore weather station is used for the TMY. Cases are assumed to be funded by a government loan with a $5 \%$ interest rate, thus an FCR of $8 \%$ is 
modelled. For the College case studies a solar multiple of 1 requires a solar field aperture area of $19500 \mathrm{~m}^{2}$.

\subsection{Case study 5 - Printing factory}

A printing factory, located in Tamilndadu, India, requires a large quantity of steam (2MW thermal yearly average) to dry textile printings. The factory currently operates on biomass alone (bio-bricks). The bio-bricks are made from sawdust, ground nut husk, coffee husk and tamarind husk, all provided by a farmer in Kerala, they are then transported to Dharapuram and made into the bio-bricks by a subsidiary company before being sent to the factory. From farmer to boiler the biomass is transported over $350 \mathrm{~km}$. The printing factory reports that the cost of the bio-bricks has increased from $16 \$$ /tonne in 2005 to a value of $100 \$ /$ tonne in 2011, and are suffering from an inconsistent feedstock supply. Thus, to reduce biomass dependency they are looking to integrate solar energy into their plant. As the printing factory uses steam directly, the plant's performance is evaluated purely on the energy delivered by the solar field and biomass boiler.

The hybrid plant for the printing factory has been modelled on the assumption that a constant steam flow rate of $0.4 \mathrm{~kg} / \mathrm{s}$, at $230^{\circ} \mathrm{C}$ and $2 \mathrm{bar}$, is required. Bio-bricks are consumed at a rate of $0.081 \mathrm{~kg} / \mathrm{s}$. The fuel composition of birch bark is assumed to have comparable properties to the bio-bricks, i.e. an LHV of $20 \mathrm{MJ} / \mathrm{kg}$. For S.M $=1$, a field aperture of $2100 \mathrm{~m}^{2}$ is required to achieve the $0.4 \mathrm{~kg} / \mathrm{s}$ steam flow rate at peak solar irradiance over the TMY. The TMY for Coimbatore is again used. The biomass boiler is modelled as either on or off. Thus, the boiler is shut down when the solar field is able to produce the demanded steam rate. Flow below $0.4 \mathrm{~kg} / \mathrm{s}$ from the solar field is therefore considered as surplus heat. At an $\mathrm{SM}>1$, further surplus energy is created for steam flows greater than $0.4 \mathrm{~kg} / \mathrm{s}$. A solar field aperture of $4200 \mathrm{~m}^{2}$ provides a solar multiple of 1 for the printing plant. The results for the plant are shown in Figure 6a-d.

\section{Discussion}

The results from the case studies will now be summarised and discussed thus providing answers to the four research questions outlined in the introduction:

\section{Q1. What is the appropriate solar multiple for a hybrid plant?}

A solar multiple varying from 1 (cases 2, 3 and 4) to 2.5 (case 5) was indicated (see Table 3) by consideration of a hybrid plant's energy and exergetic efficiencies, cost per exergetic loss, levelised costs, payback periods, and biomass and land saved. (Detailed simulation results corresponding to these solar multiples can be found in Table A.1 - see on-line annex). The variation in the recommended SM was due to differing operating conditions and financial assumptions. For the tri-generation and electricity base load studies (cases 3 and 4), the cost per exergy loss and levelised costs increased constantly with SM (Figures 4 and 5). For the peak load studies (cases 1 and 2) the addition of solar energy increased the cost per exergy loss which remained relatively constant for an increasing SM. The peak load (cases 1 and 2) and process heat (case 5) studies had a less substantial levelised cost increase for an SM = 0.5-1.5 and 1-2 respectively, which resulted in a minimum payback period for the solar 
investment being indicated. As expected the capital cost payback period increased for larger solar multiples, but increased more gradually for an $\mathrm{SM}=0.5-1.5$. For a large $\mathrm{SM}$ the biomass and land saved also became less substantial in comparison to increased values for the financial criteria.

\section{Q2. How do the levelised energy costs of alternative hybrid applications compare to other energy sources, renewable and conventional?}

The levelised energy costs for hybrid solar-biomass power plants are competitive with other renewable energy systems in India. Energy costs for the five case studies modelled were lower than photovoltaic and comparable to wind turbines (see Figure 7). Furthermore, the levelised electricity costs for all the case studies were even more attractive in comparison to the costs researched for extending India's electrical grid to rural areas, which range from 6.4$462.3 \phi / \mathrm{kWh}$ [50]. In comparison to the Gujarat pilot plant, the College case studies (cases 24), which had higher capital and operating costs, achieved lower electricity and energy cost values, due to the larger capacity of these plants. On a larger scale, the unit energy costs for the case studies are approximately two and four times what would be expected for a commercial CSP and coal fired power station in India respectively. Yet, in comparison to small scale decentralised system in India, the hybrid plants perform well with considerably lower electricity and energy cost values.

\section{Q3. How does the hybrid plant compare to a biomass-only plant?}

The hybrid plants' energy and exergetic efficiencies were largely insensitive to an increasing SM. For cases $1-3$ the heat cycle had the lowest exergetic efficiency, however exergetic efficiencies were comparable at around $20-30 \%$ for the solar field, biomass boiler and heat cycle. In comparison to a biomass-only plant, the main drawbacks of the hybrid solarbiomass power plants were financial; however there were also environmental advantages. For the selected SMs shown in Table 3 the cost per exergy loss and levelised energy cost increased from 8.3 to $24.8 \$ / \mathrm{GJ} / \mathrm{a}$ and 1.8 to $5.2 \phi / \mathrm{kWh}$ respectively in comparison to biomass-only. A more significant drawback is the long payback periods for the hybrid plant. With a high solar share, the peak load studies (cases 1 and 2) had the minimum solar investment payback period. College-base load (case 3) resulted in the lowest cost per exergy loss increase and capital cost payback period. Interestingly the College-electricity only plant (case 4, which had the lowest LCOE) has low profits without any ice production, and subsequently the payback periods for the capital and solar investment were high at 44 and 36 years respectively (see Table 3). However, payback periods for the capital cost would be decreased if larger subsidies, such as those for un-electrified rural areas of India were available, or larger facilities were built with higher performance turbines and chillers implemented. A solar field subsidy of $60 \%$ would have resulted in a capital cost payback period of 20 years for case 1 and 9 years for case 3 .

An increase in feedstock price would have resulted in the solar payback periods being considerably reduced. Biomass feedstock price for rice husk has increased significantly in recent years from $8 \$$ tonne to $50 \$ /$ tonne [7]. Kapur et al. in 1996 reported a rice husk cost of 4-20\$/tonne [53] and according to Afzal et al. the cost, in 2011, ranged from 30-60 \$/tonne 
[54]. The printing factory reports an $84 \$$ /tonne increase over a 6 years period for their biobricks. For the hybrid plant case studies it was observed that a $1.2-3.2$ times cost increase in biomass would have resulted in comparable levelised energy costs with biomass-only operation. Likewise, a $47.7-98.5 \%$ capital subsidy or cost decrease for the solar technology would have had similar results (see Table 4).

In these case studies hybridisation reduces dependency on biomass and land by around 14$29 \%$. Consequent amount of land saved will be highly dependent on biomass crop yield and supply assumptions. Crop yield is highly variable. For example, rice paddy has an upper and lower yield of 2.5-7 t/ha.a, and wheat has a yield range of 1.5-9 t/ha.a [55]. With large amounts of agricultural waste produced in India, such as coconut shells, sawdust and rice husk, it could be argued that there is no land requirement to grow these fuels. However, these agro-wastes still need to be prepared (dried), transported and stored, which accounts for the majority of the biomass cost. Furthermore, in certain regions of India, land is expensive and availability is low. Water shortage is also causing difficulties with growing biomass crops, especially as agricultural land is used for growing edible crops. Therefore, the reduced dependency on biomass in these hybrid plants is considered a significant benefit due to increasing feedstock prices, biomass exploitation and transportation and storage difficulties [56].

Q4. Which is the most feasible application for a hybrid solar-biomass power plant; trigeneration, electricity generation or industrial process heat?

The feasibility of alternative hybrid solar-biomass power plant applications will be highly dependent on regional energy policies. For the case studies presented, which assumed similar financing and key design priorities, the tri-generation and industrial process heat applications are considered to be feasible for a hybrid plant, providing the plant is carefully designed to maximise the efficient use of reject heat. Among the case studies, a tri-generation base load hybrid plant scenario (case 4) resulted in the lowest cost per exergy loss (13.9 \$/GJ/a), levelised energy cost $(18.1 \notin / \mathrm{kWh})$ and capital cost payback period (18 years). A constant base load mode of operation improves the viability of a hybrid system, increasing plant efficiencies and reducing the cost per exergy loss, levelised energy cost and capital cost payback period. Hybrid plants for off-grid applications in India, eligible for a 60\% capital subsidy, present an even more attractive option for investors. With the current technologies on the market, however, larger subsidies would be required for an electricity only plant at the less than $10 \mathrm{MW}$ scale. An off-grid tri-generation plant is recommended as the most feasible application for a hybrid solar-biomass power plant and should therefore be the focus for policymakers and renewable energy power plant developers in India.

\subsection{Further work}

The case studies have covered alternative financial baseline values, e.g. feedstock price, fixed charge rate, component costs and capital subsidies. However, the monetary values assumed could be further varied to investigate the sensitivity of levelised energy/electricity costs and payback periods. Additional factors could be considered such as, inflation, tax, varying annual feedstock prices and alternative worldwide site locations with varying capital 
subsidies and tariffs. Further applications for the effective use of reject heat should also be modelled. For example, alternative refrigeration systems - air conditioning, multi-effect distillation and double effect absorption chillers - could be considered. Applications of the hybrid tri-gen plant to the food processing industry could also be investigated further, such as, plant integration with a rice mill, where the husk would provide some of the biomass fuel. Reject heat could be used for feed water pre-heating, which will improve plant efficiency and reduce costs as the solar thermal field size could be decreased due to a higher inlet temperature. Thermal storage options in DSG systems, will improve efficiencies, solar share, load stability and reduce costs and payback periods. One type of thermal storage, the steam accumulator, currently offers one of the best options to improve load stability, compensating for the fast transients in DSG. Accumulators act as a storage buffer and have been successfully integrated in several solar thermal projects $[57,58]$.

A more detailed energy and exergy analysis of a hybrid plant's components (pumps, turbine stages, chiller, feed-water heaters, fans, condenser, deaerator, storage tanks, etc.) could be carried out to investigate the major sources of irreversibilities and thus identify which components would benefit the most from technological improvements. Optimisation of a plant's operating temperature could also be achieved by extension of the energy-exergy analysis. Indeed, improvements can be made to hybrid plants and future case specific studies will require more detailed analysis. An interesting study would be a detailed comparison of hybrid LFR- and PTC-biomass power plants.

The modelling has assumed several simplifications regarding the control of the plants. The mass flow in the solar field was controlled to achieve a constant temperature and pressure. However, in practice this is difficult as overshoot can occur. The concept of hybridising solar and biomass for steam generation to power directly a turbine raises numerous control challenges. There are a number of non-linear variables and steam turbines only tolerate temperature and load fluctuations of a few degrees and percent per minute [58]. Superheated steam generated directly in the solar field exhibits fast transients as a result of the variable solar input and demand changes at the boiler, and this can result in difficulties with maintaining drum pressure and water level. Thus, hybrid solar-biomass power plants will require high-quality control systems which should be the focus of further work. One manufacturer of an LFR system claims that they have already developed a predictive control system that is capable of maintaining pressure, temperature and flow for varying solar inputs [59]. By implementing suitable control strategies a fast boiler response time, and constant pressure, temperature and flow should also be achievable. Kalogirou [60] presents a comprehensive review on artificial intelligence systems for combustion processes, including boilers and gas engines. However, the best control scheme for a steam boiler to attain a fast response is an open problem.

The solar multiple could also have been selected using decision-making techniques. Multicriteria decision-making (MCDM) procedures have been used in renewable energy planning to rank alternatives for explicitly better and more informed decisions [61]. To specify a suitable solar multiple for a hybrid plant, an MCDM strategy would be particularly useful as 
it is a multifaceted problem with a number of potential criteria to consider. Detailed design priorities for a hybrid plant application could also be established using MCDM methods to facilitate discussion among designers and stakeholders.

\section{Conclusion}

Having considered the answers to the research questions posed in this paper, the future prospects for hybrid solar-biomass power plants are now addressed.

For small-mid scale applications (2-10 MW thermal), hybrid solar-biomass power plants are currently a feasible option for tri-generation (electricity, cooling and heat) in India, providing solar capital subsidies remain in place (30\% grid-connected, $60 \%$ off-grid). Industrial process heat also presents a viable option for applications with an effective utilisation of heat. At these scales there are better options for generating electricity only. However, hybrid solarbiomass power plants will become an increasingly attractive option as steam energy storage methods improve, solar thermal costs decrease and biomass feedstock and fossil fuel prices rise. Focus should be given to making technological improvements to the heat cycle of small scale hybrid plants due to low energy and exergetic efficiencies. While biomass-only systems are currently more economically viable, for a small levelised energy cost increase (1.8-5.2 $\phi / \mathrm{kWh}$ ), hybrid systems can play an important role in tackling the biomass supply chain issues in India and worldwide (14-29\% biomass and land reduction). Furthermore, the price of biomass is rapidly rising and an additional $1.2-3.2$ times increase will result in hybrid systems becoming cost competitive with biomass-only. It is concluded that energy policymakers in India should prioritise subsidies for hybrid tri-generation systems to promote the concept to potential investors and plant developers, thus establishing the technology in the market. Hybrid plants should be up-scaled in India for electricity generation; this would aid in keeping solar thermal a competitive option in comparison to alternative renewable energy technologies and establish India as a global leader on hybrid solar-biomass power systems.

\section{Acknowledgments}

The authors would like to acknowledge the financial support under the Science Bridge project financed by Research Councils UK (EP/G039992/1) and Department of Science and Technology, India, along with the contributions of colleagues at IIT Delhi and Industrial Boilers Ltd. The authors would also like to acknowledge the data provided by our colleague Vimal Eswarlal and the company Siemens.

\section{References}

[1] MNRE. Guidelines for off-grid and decentralised solar applications. 2010.

[2] Government of India, National Action Plan on Climate Change. 2008.

[3] Montes MJ, Abánades A, Martínez-Val JM. Performance of a direct steam generation solar thermal power plant for electricity production as a function of the solar multiple. Solar Energy. 2009;83(5):679-89.

[4] Birnbaum J, Eck M, Fichtner M, Hirsch T, Lehmann D, Zimmermann G. A Direct Steam Generation Solar Power Plant With Integrated Thermal Storage. Journal of Solar Energy Engineering. 2010;132(3):031014. 
[5] Hoshi A, Mills DR, Bittar A, Saitoh TS. Screening of high melting point phase change materials (PCM) in solar thermal concentrating technology based on CLFR. Solar Energy. 2005;79(3):332-9.

[6] Suresh C. Biomass resources assessment for power generation: A case study from Haryana state, India. Biomass and Bioenergy. 2010;34(9):1300-8.

[7] Mohan B, K. Rising fuel costs make biomass energy unattractive. Business Standard; 2009.

[8] Ravindranath NH, Somashekar HI, Nagaraja MS, Sudha P, Sangeetha G, Bhattacharya $\mathrm{SC}$, et al. Assessment of sustainable non-plantation biomass resources potential for energy in India. Biomass and Bioenergy. 2005;29(3):178-90.

[9] Kaushika N, Mishra A, Chakravarty M. Thermal analysis of solar biomass hybrid cogeneration plants. International Journal of Sustainable Energy. 2005;24(4):175-86.

[10] Dimityr P. An option for solar thermal repowering of fossil fuel fired power plants. Solar Energy. 2011;85(2):344-9.

[11] Lerchenmüller H, Mertins M, Morin G. Fresnel-Collectors in hybrid Solar Thermal Power Plants with high Solar Shares. Fraunhofer Institute for Solar Energy Systems; 2004. [12] Bermejo P, Pino FJ, Rosa F. Solar absorption cooling plant in Seville. Solar Energy. 2010;84(8):1503-12.

[13] Cot A, Ametller A, Vall-llovera J, Aguiló J, Arque JM. Termosolar Borges: A Thermosolar Hybrid Plant with Biomass. Third International Symposium on Energy from Biomass and Waste. Venice, Italy 2010.

[14] Solarlite. TRESERT Phitsanulok, Thailand.

[15] Cost Reduction Study for Solar Thermal Power Plants. The World Bank Washington, D.C.; 1999.

[16] Kosugi T, Pak PS. Economic evaluation of solar thermal hybrid $\mathrm{H} 2 \mathrm{O}$ turbine power generation systems. Energy. 2003;28(3):185-98.

[17] Frebourg P, Ketjoy N, Nathakaranakul S, Prontornkulpanich A, Rakwichian W, Laodee

P. Feasibility Study of a Small-Scale Grid-Connected Solar Parabolic Biomass Hybrid Power Plant in Thailand.

[18] Beerbaum S, Weinrebe G. Solar thermal power generation in India-a techno-economic analysis. Renewable Energy. 2000;21(2):153-74.

[19] Bhattacharya A, Manna D, Paul B, Datta A. Biomass integrated gasification combined cycle power generation with supplementary biomass firing: Energy and exergy based performance analysis. Energy. 2011;36(5):2599-610.

[20] Vidal A, Best R, Rivero R, Cervantes J. Analysis of a combined power and refrigeration cycle by the exergy method. Energy. 2006;31(15):3401-14.

[21] Singh N, Kaushik S, Misra R. Exergetic analysis of a solar thermal power system.

Renewable Energy. 2000;19(1-2):135-43.

[22] Rosen MA. A concise review of exergy-based economic methods. Conference A concise review of exergy-based economic methods. World Scientific and Engineering Academy and Society (WSEAS), p. 136-44.

[23] Kanoglu M, Dincer I, Rosen MA. Understanding energy and exergy efficiencies for improved energy management in power plants. Energy Policy. 2007;35(7):3967-78.

[24] Baghernejad A, Yaghoubi M. Exergoeconomic Analysis and Optimization of Solar Thermal Power Plants.

[25] Rosen MA, Dincer I. Exergoeconomic analysis of power plants operating on various fuels. Applied Thermal Engineering. 2003;23(6):643-58.

[26] Kaushik SC, Abhyankar YP, Bose S, Mohan S. Exergoeconomic Evaluation of a Solar Thermal Power Plant. International Journal of Solar Energy. 2001;21(4):293-314. 
[27] Hepbasli A. A key review on exergetic analysis and assessment of renewable energy resources for a sustainable future. Renewable and Sustainable Energy Reviews.

2008;12(3):593-661.

[28] (USTDA) USTaDA. Building capacity in India's cold chain infrastructure. US - Inida Agriculture Knowledge Initiative Program.

[29] TRNSYS17. A TRaNsient SYstems Simulation Program. The University of Wisconsin. [30] Morin G, Dersch J, Platzer W, Eck M, Häberle A. Comparison of Linear Fresnel and Parabolic Trough Collector power plants. Solar Energy. 2012;86(1):1-12.

[31] Song G, Shen L, Xiao J. Estimating Specific Chemical Exergy of Biomass from Basic Analysis Data. Industrial \& Engineering Chemistry Research. 2011;50(16):9758-66.

[32] Luo HL, Dai YJ, Wang RZ, Tang R, Li M. Year round test of a solar adsorption ice maker in Kunming, China. Energy Conversion and Management. 2005;46(13-14):2032-41. [33] Morin G, Platzer W, Strelow M, Leithner R. Techno-Economic System Simulation and Optimisation of Solar Thermal Power Plants. SolarPaces. Las Vegas, USA 2008.

[34] Nixon JD, Dey PK, Davies PA. Which is the best solar thermal collection technology for electricity generation in north-west India? Evaluation of options using the analytical hierarchy process. Energy. 2010;35(12):5230-40.

[35] Graham J, Storbritannien. Ministry of Agriculture F, Food. Icemaking plant. Aberdeen: Torry Research Station, 1975.

[36] Industrial Boilers Ltd.

[37] MinistryofNewandRenewableEnergy. Guidelines for Generation Based Incentive, Grid Interactive Solar Thermal Power Generation Projects. 2008.

[38] Potential outputs of biofuels per hectare, per annum. Biomass Energy Centre; 2008.

[39] Jones S.A. BN, Pitz-Paal R., Schwarzboezl P. and Cable B. TRNSYS Modeling of the

SEGS VI Parabolic Trough Solar Electric Generating System. Conference TRNSYS

Modeling of the SEGS VI Parabolic Trough Solar Electric Generating System, Washington, DC.

[40] Stuetzle T. BN, Mitchell J.W., Beckman W.A. Automatic Control of a 30 MWe SEGS VI Parabolic Trough Plant. Conference Automatic Control of a 30 MWe SEGS VI Parabolic Trough Plant.

[41] TRNLIB - Libraries of User-Written Components for TRNSYS. The University of Wisconsin Madison.

[42] Werther J, Saenger M, Hartge EU, Ogada T, Siagi Z. Combustion of agricultural residues. Progress in Energy and Combustion Science. 2000;26(1):1-27.

[43] Thipwimon C, Gheewala Shabbir H, Suthum P. Environmental assessment of electricity production from Rice Husk: A case study in Thailand. Electricity supply industry in transition: issues and prospect for Asia. 2004;20:51-62.

[44] Ayhan D. Calculation of higher heating values of biomass fuels. Fuel. 1997;76(5):431-4. [45] Ayhan D. Combustion characteristics of different biomass fuels. Progress in Energy and Combustion Science. 2004;30(2):219-30.

[46] Nixon JD, Davies PA. Cost-exergy optimisation of linear Fresnel reflectors. Solar Energy. 2012;86(1):147-56.

[47] Kalogirou SA. Solar thermal collectors and applications. Progress in Energy and Combustion Science. 2004;30(3):231-95.

[48] Duffie JA, Beckman WA. Solar engineering of thermal processes. 3rd ed. New York: John Wiley \& Sons, 2006.

[49] Melinder A. Thermophysical Properties of Aqueous Solutions Used as Secondary

Working Fluids [Doctoral Thesis]. Stockholm, Sweden: Royal Institute of Technology, KTH, 2007. 
[50] Nouni MR, Mullick SC, Kandpal TC. Providing electricity access to remote areas in India: An approach towards identifying potential areas for decentralized electricity supply. Renewable and Sustainable Energy Reviews. 2008;12(5):1187-220.

[51] Rangan B. Comparison of options for distributed generation in India. Energy Policy. 2006;34(1):101-11.

[52] Nouni MR, Mullick SC, Kandpal TC. Providing electricity access to remote areas in India: Niche areas for decentralized electricity supply. Renewable Energy. 2009;34(2):430-4. [53] Kapur T, Kandpal TC, Garg HP. Electricity generation from rice husk in Indian rice mills: Potential and financial viability. Biomass and Bioenergy. 1996;10(5-6):393-403. [54] Afzal A, Mohibullah M, Sharma VK. Performance analysis of a rice husk power generating system: a case study. International Journal of Sustainable Energy. 2011;30(1):110.

[55] Fischer G, Prieler S, van Velthuizen H, Berndes G, Faaij A, Londo M, et al. Biofuel production potentials in Europe: Sustainable use of cultivated land and pastures, Part II: Land use scenarios. Biomass and Bioenergy. 2010;34(2):173-87.

[56] Rentizelas AA, Tolis AJ, Tatsiopoulos IP. Logistics issues of biomass: The storage problem and the multi-biomass supply chain. Renewable and Sustainable Energy Reviews. 2009;13(4):887-94.

[57] Medrano M, Gil A, Martorell I, Potau X, Cabeza LF. State of the art on hightemperature thermal energy storage for power generation. Part 2-Case studies. Renewable and Sustainable Energy Reviews. 2010;14(1):56-72.

[58] Raphael A. Superheated Direct Steam Generation. SolarPACES. Granada, Spain 2011. [59] Conlon W. Superheated Steam from CLFR Solar. SolarPACES. Granada, Spain 2011. [60] Kalogirou SA. Artificial intelligence for the modeling and control of combustion processes: a review. Progress in Energy and Combustion Science. 2003;29(6):515-66. [61] Pohekar SD, Ramachandran M. Application of multi-criteria decision making to sustainable energy planning--A review. Renewable and Sustainable Energy Reviews. 2004;8(4):365-81.

\section{Figures and tables}

Figure 1: General schematic of a hybrid LFR-biomass power plant for tri-generation.

Figure 2a-d: Gujarat pilot plant (case study 1) shows: (a) the minimum energy and exergetic efficiencies occur at the heat cycle, and the overall system energy and exergetic efficiencies decrease relatively constantly from 0.067 to 0.042 and 0.056 to 0.040 for $\mathrm{SM}=0-2$; (b) the overall system cost per exergy loss increases by hybridising with solar, but remains relatively constant for larger SMs; (c) the levelised costs of electricity and energy remains relatively constant among the SM alternatives, around 72 and $22 \phi / \mathrm{kWh}$ respectively, and a solar multiple of 1 to 1.5 results in the minimum payback period for the solar investment (33 years) and a capital cost payback period of 34 to 39 years; (d) the biomass and land saving becomes less substantial for SM $>1$, at $\mathrm{SM}=$ 1 the hybrid plant saves 1800 tonnes and 140 hectares per annum.

Figure 3a-d: College-peak load (case study 2) shows: (a) the minimum energy and exergetic efficiencies occur at the heat cycle, and the overall system energy and exergetic efficiencies decrease relatively constantly from 0.071 to 0.044 and 0.059 to 0.043 for $\mathrm{SM}=0-2$; (b) the overall system's cost per exergy loss increases by hybridising with solar, but remains relatively constant for larger SMs. The heat cycle's cost per exergy loss decreases constantly for larger SMs; (c) the levelised electricity and energy costs increase relatively constantly for an increasing $\mathrm{SM}$, and an $\mathrm{SM}=1$ results in the minimum solar payback period and a capital cost payback period of 38 years; (d) the biomass and land saving becomes less substantial for SM $>1$, at SM $=1$ the hybrid plant saves 2500 tonnes and 188 hectares per annum. 
Figure 4a-d: College-base load (case study 3) shows: (a) the minimum energy efficiencies occur at the heat cycle and solar filed and minimum exergetic efficiencies occur at the heat cycle. The overall system energy and exergetic efficiencies decrease relatively constantly from 0.087 to 0.049 and 0.072 to 0.055 for $\mathrm{SM}=0-2$; (b) the overall system cost per exergy loss increases constantly for larger SMs; (c) the levelised electricity and energy cost increase constantly for larger solar multiples, and an $\mathrm{SM}=1$ results in the minimum solar payback period (62 years) and a capital cost payback period of 18 years; (d) the biomass and land saving remains constant for an increasing SM, at SM $=1$ the hybrid plant saves 3100 tonnes and 240 hectares per annum.

Figure 5a-d: College-electricity (case study 4) shows: (a) the minimum energy efficiencies occur at the solar filed and minimum exergetic efficiencies occur at the heat cycle. The overall system energy and exergetic efficiencies decrease relatively constantly from 0.118 to 0.079 and 0.098 to 0.073 for $\mathrm{SM}=0-2$; (b) the overall system cost per exergy loss increases constantly for larger SMs; (c) the levelised electricity and energy costs increase constantly from around 11.5 to $17 \mathrm{\phi} / \mathrm{kWh}$ for an SM of $0-2$, and a capital cost and solar investment payback period of 44 and 36 years respectively for an $\mathrm{SM}=1$; (d) the biomass and land saving remains constant for an increasing SM, at SM $=1$ the hybrid plant saves 3100 tonnes and 240 hectares per annum.

Figure 6a-d: Printing factory (case study 5) shows: (a) the minimum energy and exergetic efficiencies occur at the solar field. The overall system energy and exergetic efficiencies decrease relatively constantly from 0.687 to 0.554 and 0.603 to 0.533 for $\mathrm{SM}=0-2$; (b) the cost per exergy loss of the overall system and solar field increases and decreases respectively for larger SMs; (c) the levelised energy cost increases from 3.2 to $4 \notin / \mathrm{kWh}_{\mathrm{t}}$ for an $\mathrm{SM}$ of 0 to 3, and a minimum payback period of 88 years for $\mathrm{SM}=2.5$; (d) the biomass and land saving remains constant for an increasing SM from 1 to 2, at $\mathrm{SM}=2.5$ the hybrid plant saves 500 tonnes and 40 hectares per annum.

Figure 7: Levelised electricity and energy costs for the five case studies compared to the levelised cost of electricity for small and large scale energy systems in India, reported by Rangan [51], Nouni et al. [52] and Beerbaum and Weinrebe [18].

Table 1: The five case studies and their applications, operational conditions and financing.

Table 2: Specifications for the BT-4, STT-060 and condensing steam turbine.

Table 3: Selected solar multiple for the five case studies (see Table 1) and the resulting energy and exergy efficiency, cost per exergy loss increase in comparison to a biomass only plant, levelised electricity and energy costs (including cost increase in comparison to a biomass-only plant), payback periods and biomass and land saved.

Table 4: Solar field subsidy and cost of biomass for the hybrid plants with selected SM to be cost competitive with biomass only operation, i.e. same levelised energy costs. 


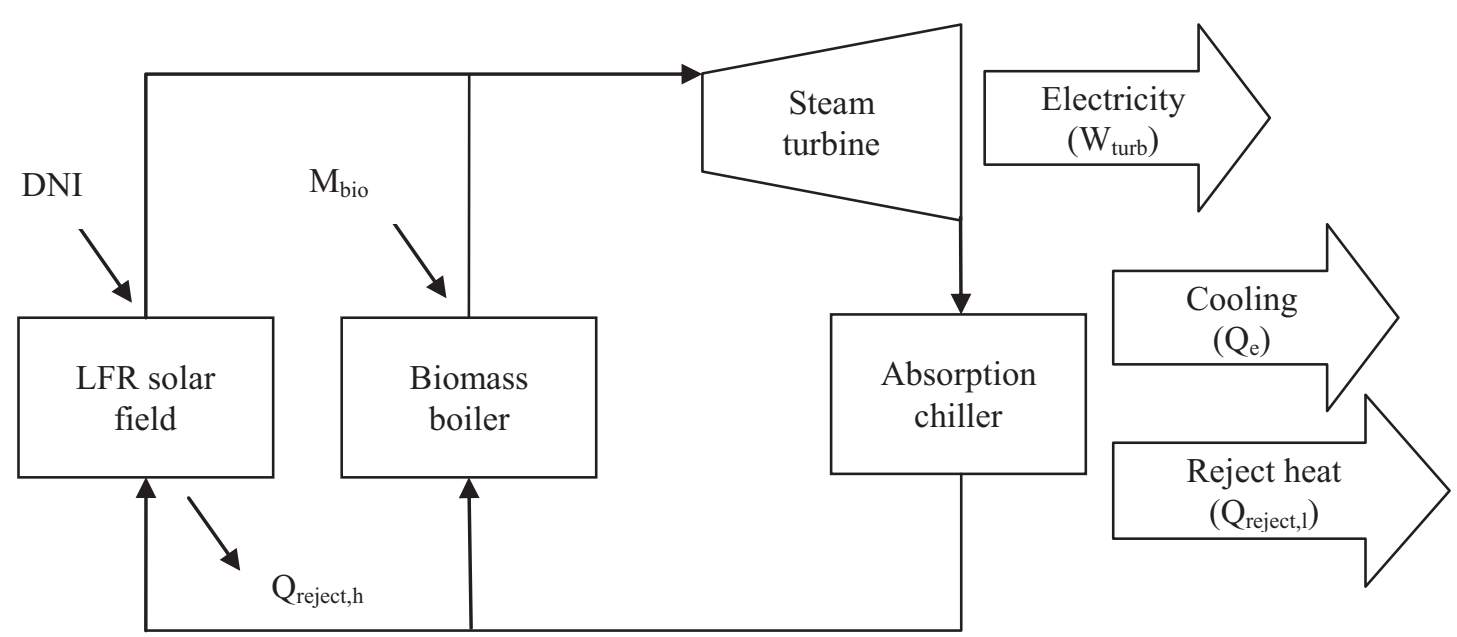

Figure 1 


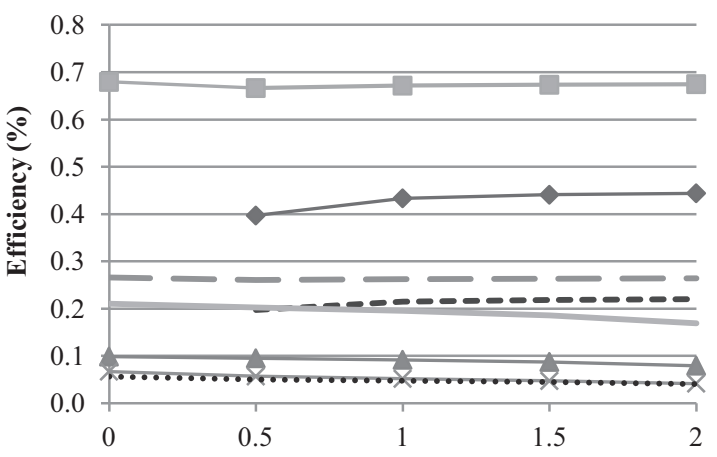

(2a) Solar multiple

$\multimap \eta \mathrm{I}, \mathrm{c} \longrightarrow \eta \mathrm{I}, \mathrm{b} \longrightarrow \eta \mathrm{I}, \mathrm{hc} \longrightarrow \eta \mathrm{I}, \mathrm{os}$ $---\eta \mathrm{II}, \mathrm{c} \longrightarrow \eta \mathrm{II}, \mathrm{b} \longrightarrow \eta \mathrm{II}, \mathrm{hc} \quad \cdots \cdots \cdot \eta_{\mathrm{II}, \mathrm{os}}$

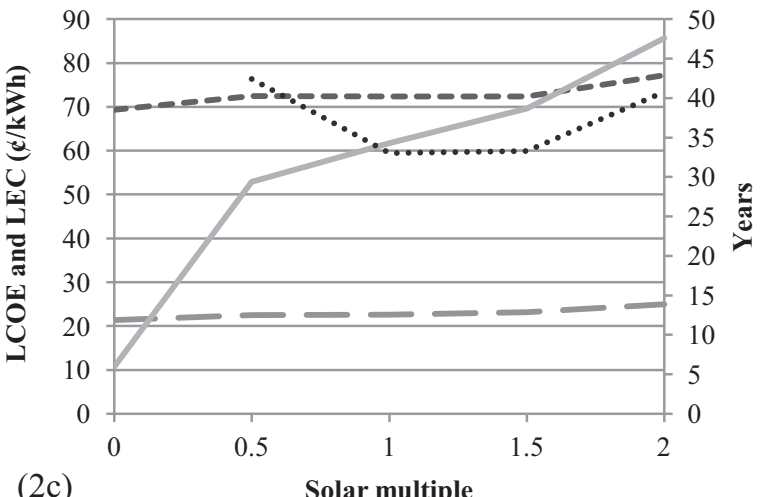

---- LCOE — - LEC $\longrightarrow$ PPcap ….... PPsol

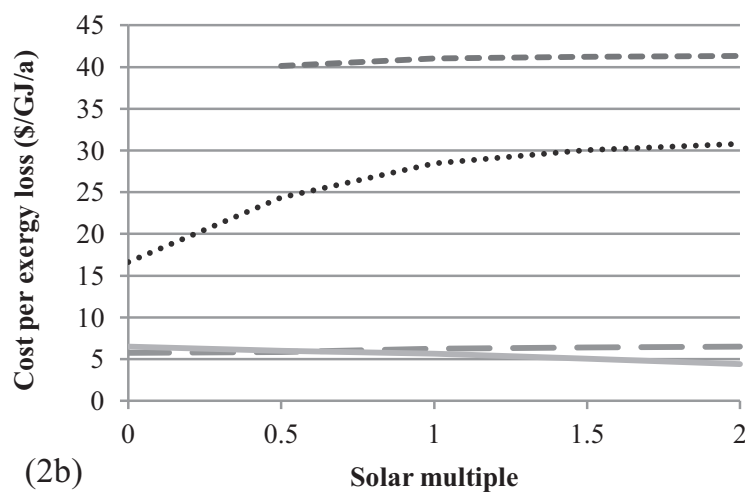

-- Cpel,c - Cpel,b $\longrightarrow$ Cpel,hc $\cdots . . .$. Cpel,os

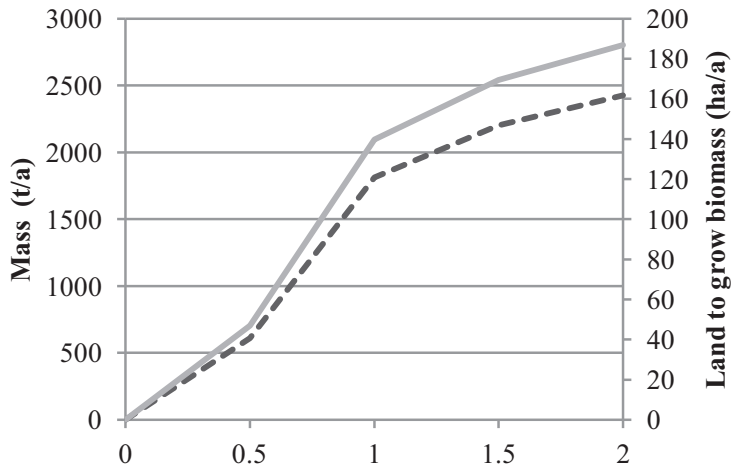

(2d)

Solar multiple

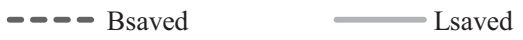

Figure 2a-d 


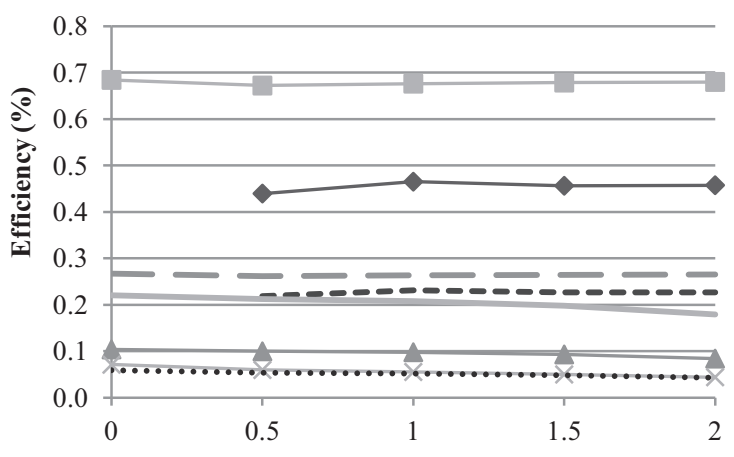

(3a)

Solar multiple
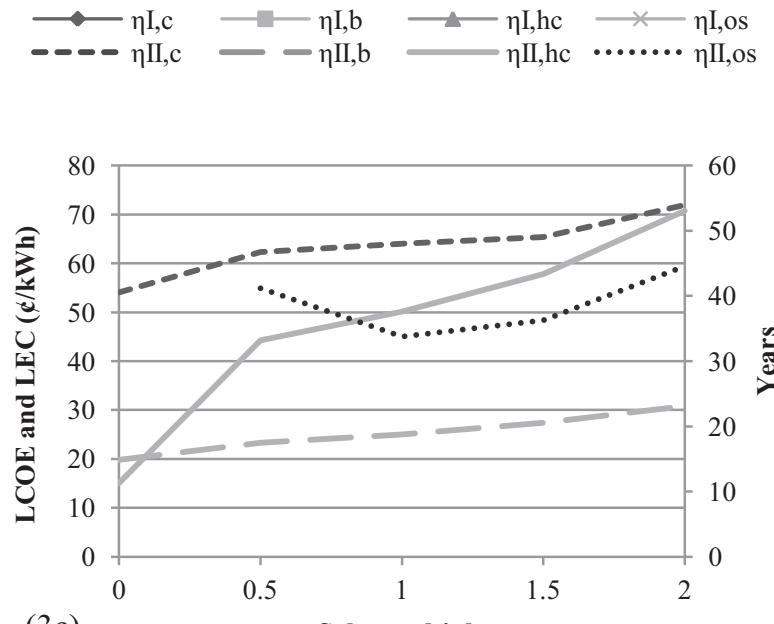

(3c)

Solar multiple

--- LCOE - - LEC $\longrightarrow$ PPcap ........ PPsol

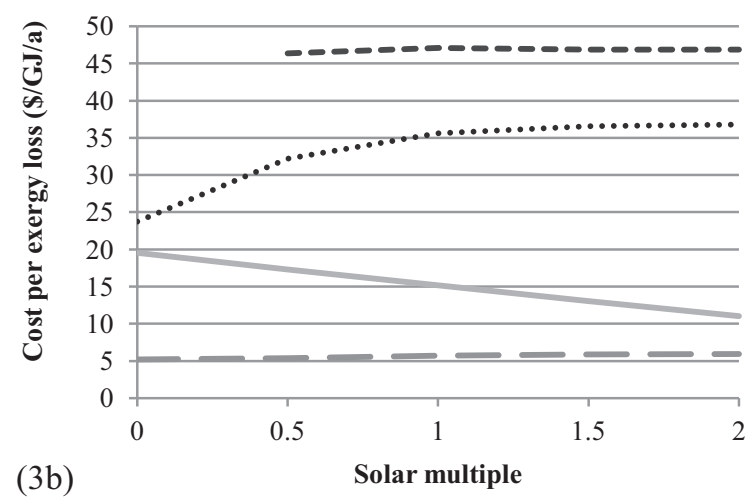

--- Cpel,c - Cpel,b Cpel,hc $\cdots . . .$. Cpel,os

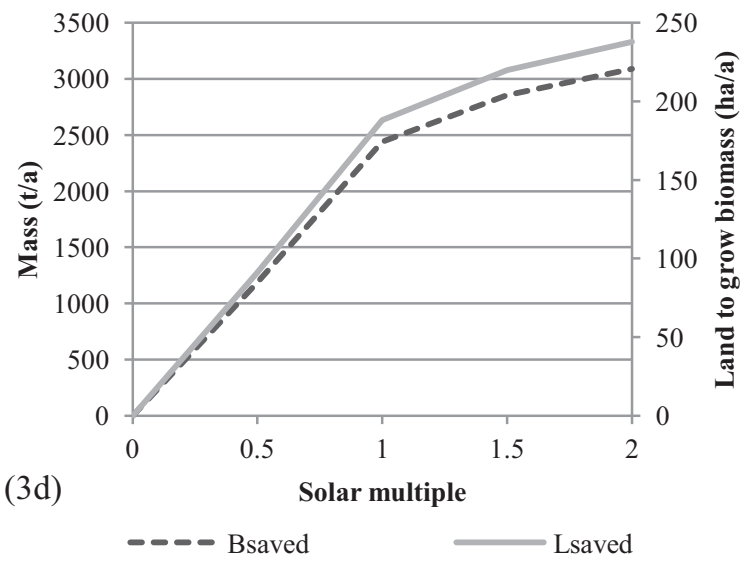

Figure $3 a-d$ 


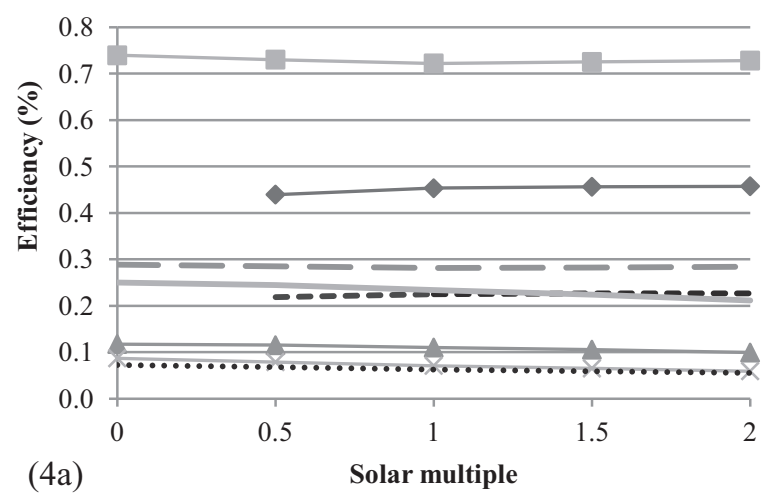

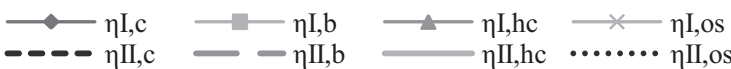

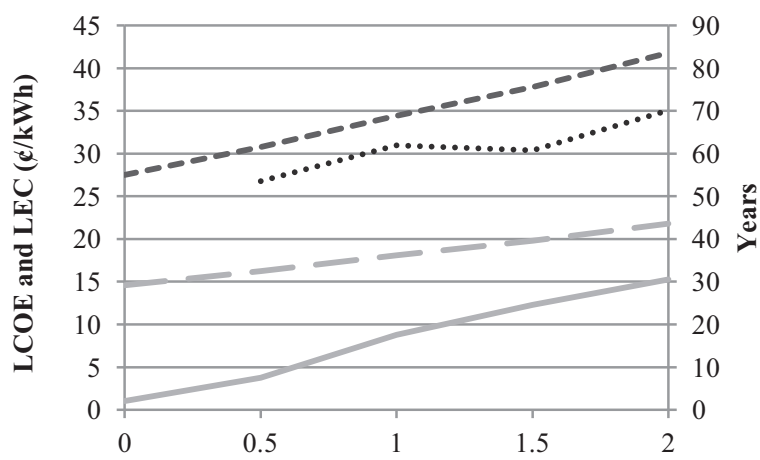

(4c)

Solar multiple

--- LCOE - - LEC — PPcap ....... PPsol

Figure $4 a-d$

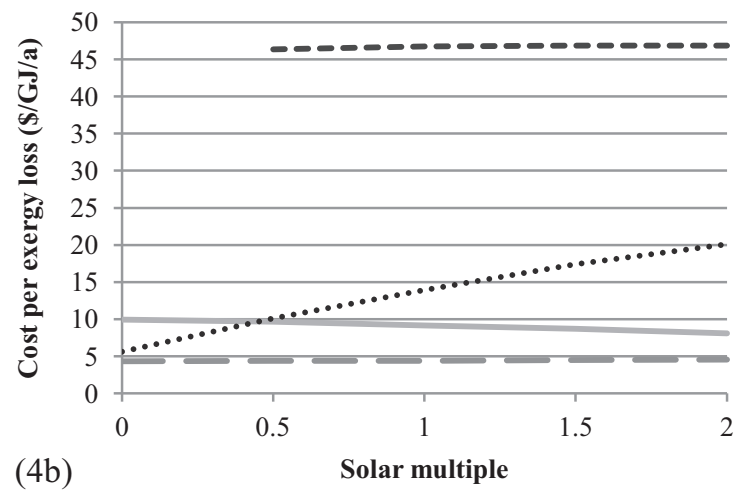

--- Cpel,c - Cpel, b Cpel,hc ….... Cpel,os

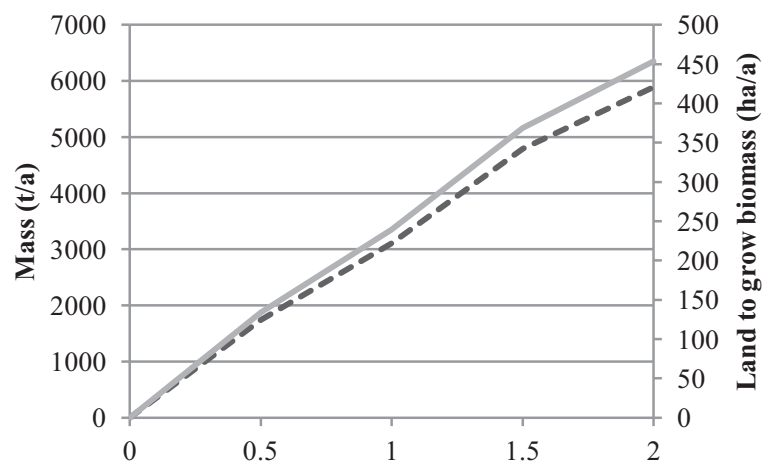

(4d)
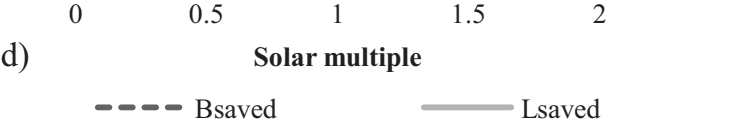


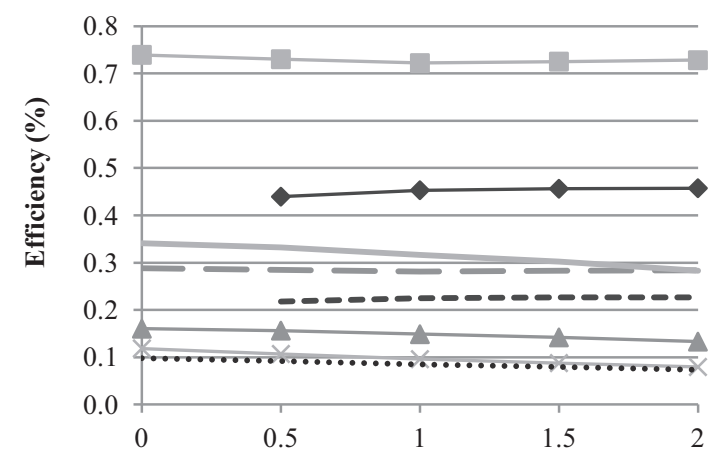

(5a)

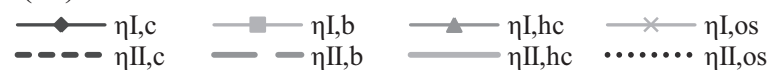

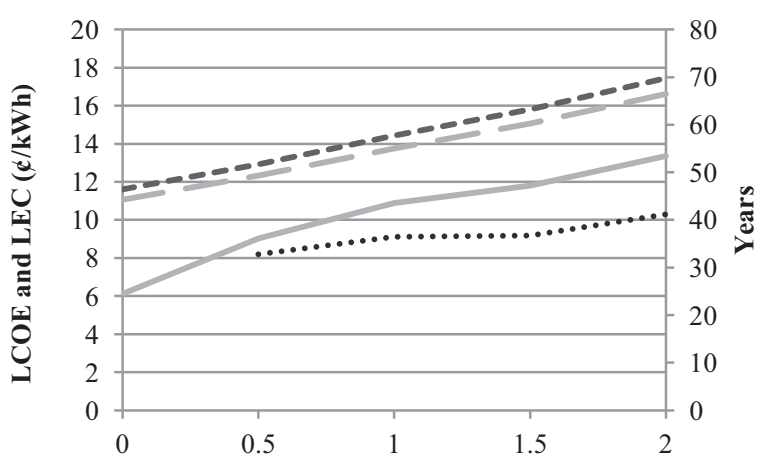

(5c)

Solar multiple

- - - LCOE - - LEC $\longrightarrow$ PPcap ........ PPsol

Figure 5a-d

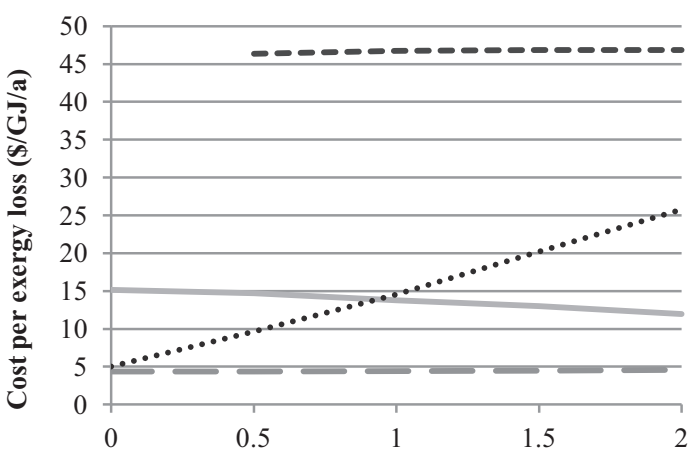

(5b)

Solar multiple

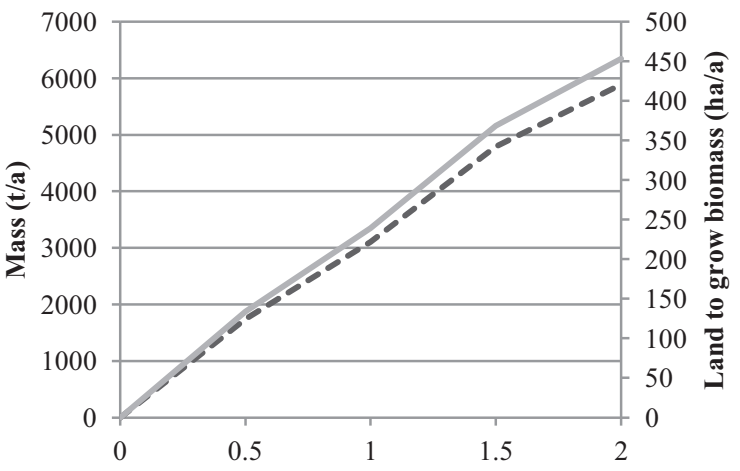

(5d)

- - Bsaved L Lsaved

Cpel,os

0 苞

350 \%

250

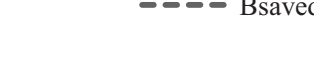



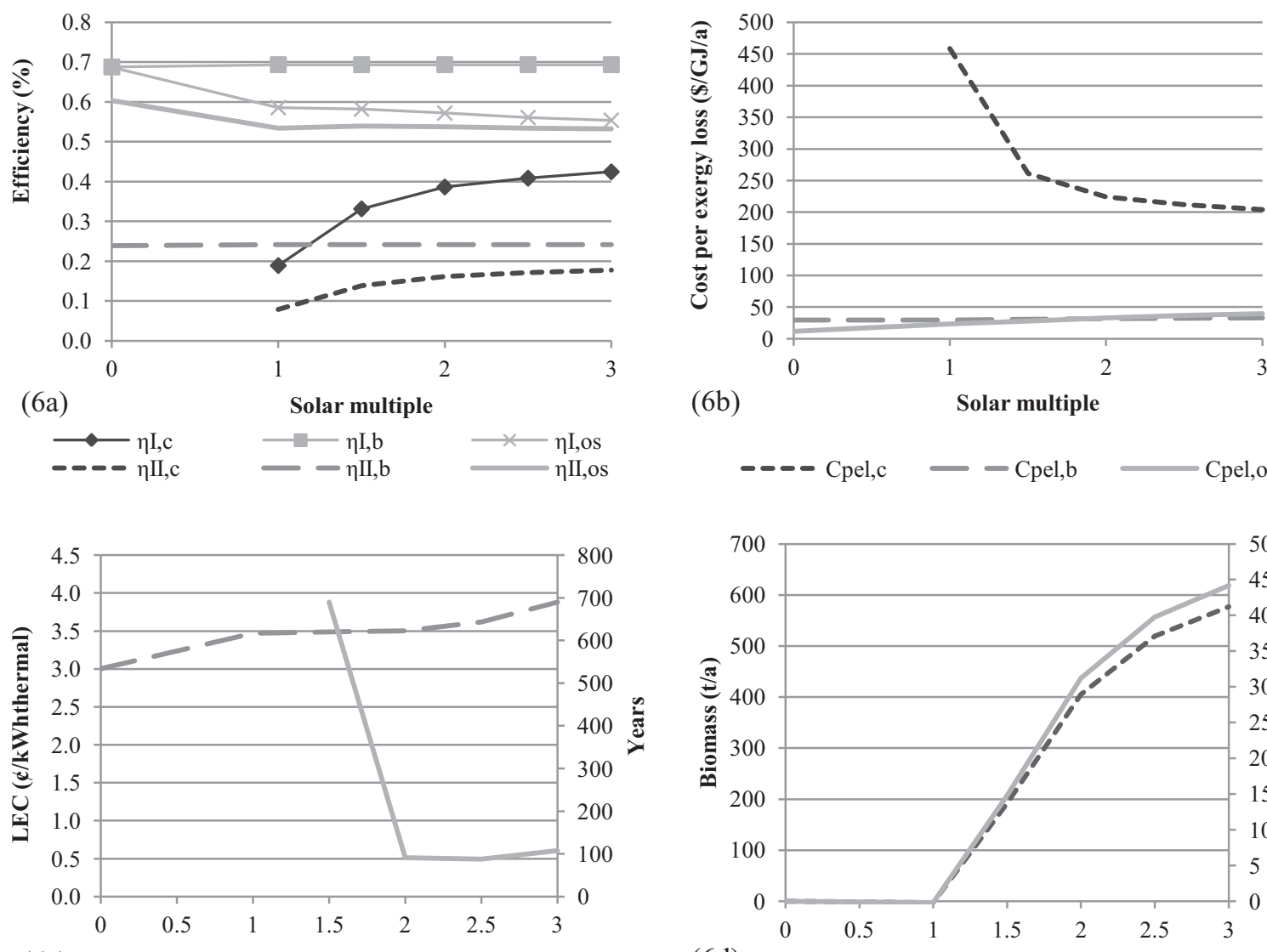

(6c)

Solar multiple
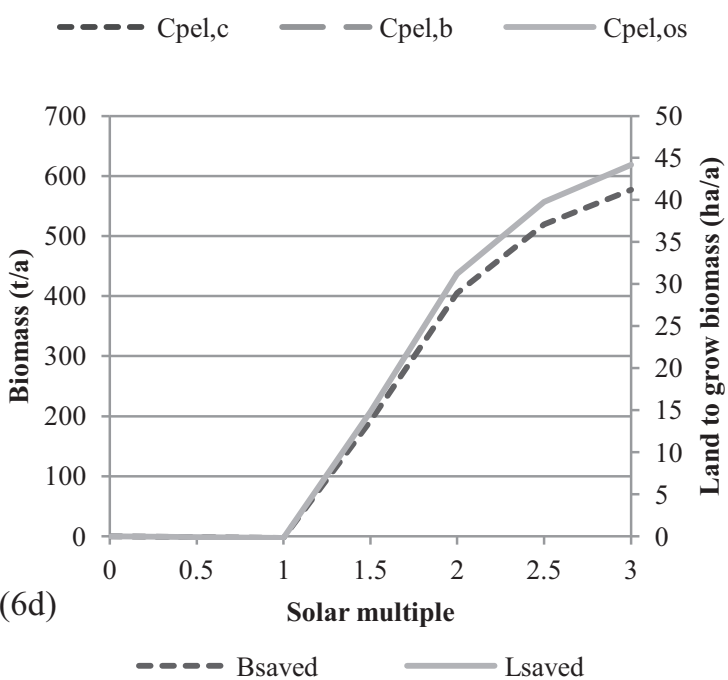

Figure 6a-d 
Figure 7

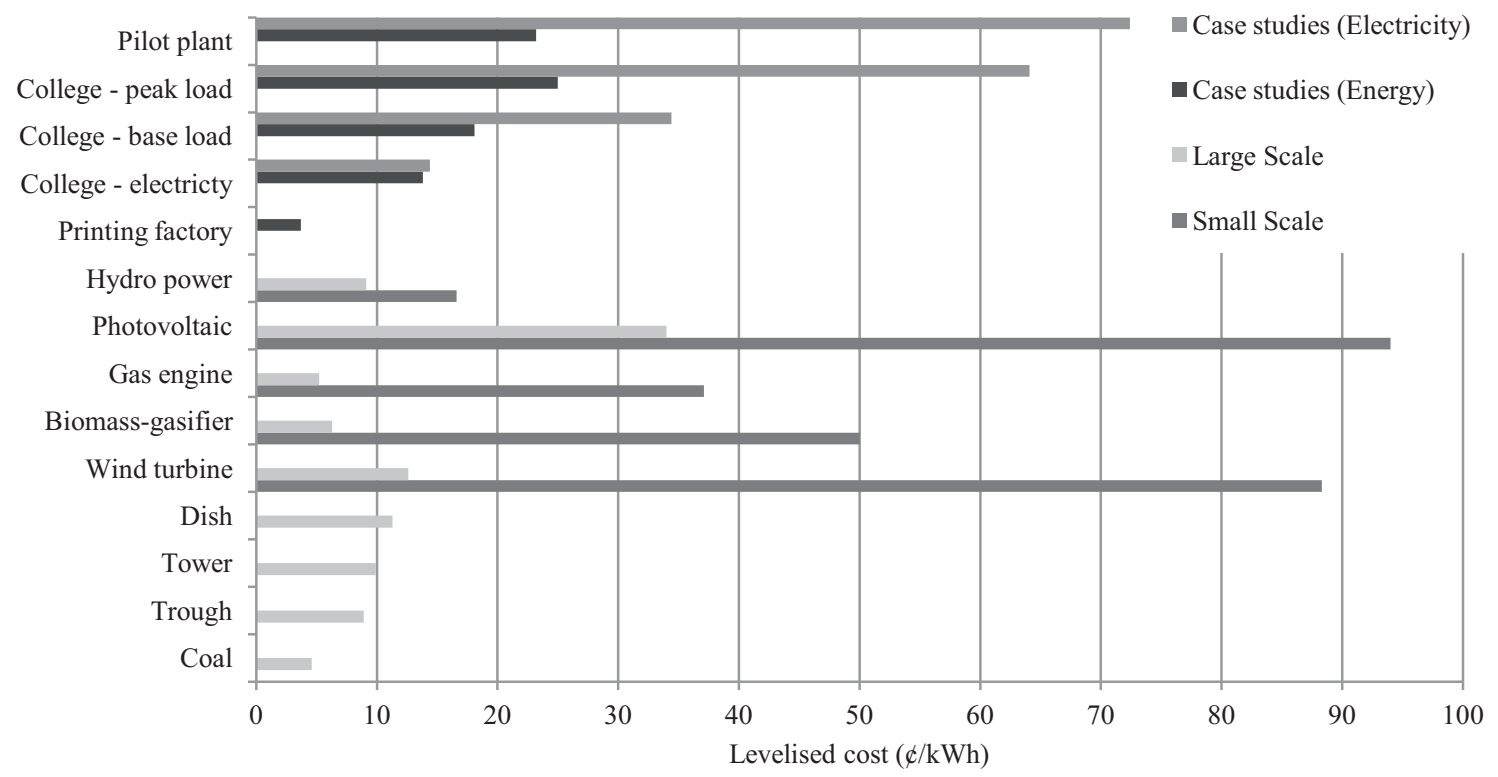

Figure 7 


\begin{tabular}{lccccc} 
Case study & (1) Gujarat & (2) College & (3) College & (4) College & (5) Printing \\
& pilot plant & - peak load & - base load & - electricity & factory \\
\hline Application & Tri-gen & Tri-gen & Tri-gen & Electricity-only & Process heat \\
Demand load & Peak & Peak & Base & Base & Base \\
Location & Gujarat & Tamilnadu & Tamilnadu & Tamilnadu & Tamilnadu \\
Peak capacity & $5 \mathrm{MW}_{\text {thermal }}$ & $10 \mathrm{MW}_{\text {thermal }}$ & $10 \mathrm{MW}$ thermal & $10 \mathrm{MW}$ thermal & $2 \mathrm{MW}_{\text {thermal }}$ \\
Fixed charge rate & $5 \%$ & $8 \%$ & $8 \%$ & $8 \%$ & $8 \%$ \\
Capital subsidy & $30 \%$ & $30 \%$ & $30 \%$ & $30 \%$ & $30 \%$ \\
Feedstock & Rice husk & Coconut shell & Coconut shell & Coconut shell & Bio-brick \\
Feedstock LHV & $14 \mathrm{MJ} / \mathrm{kg}$ & $16 \mathrm{MJ} / \mathrm{kg}$ & $16 \mathrm{MJ} / \mathrm{kg}$ & $16 \mathrm{MJ} / \mathrm{kg}$ & $20 \mathrm{MJ} / \mathrm{kg}$ \\
Feedstock price & $40 \$ /$ tonne & $50 \$ /$ tonne & $50 \$ /$ tonne & $50 \$ /$ tonne & $100 \$ /$ tonne \\
\hline
\end{tabular}

Table 1 
Table 2

\begin{tabular}{lccccccccc} 
Turbine & $m_{\text {turb }}$ & $\begin{array}{c}\mathrm{P}_{\text {inlet }} \\
\mathrm{kg} / \mathrm{s}\end{array}$ & $\begin{array}{c}\mathrm{P}_{\text {exit }} \\
\text { bar }\end{array}$ & $\begin{array}{c}\mathrm{T}_{1} \\
{ }^{\circ} \mathrm{C}\end{array}$ & $\begin{array}{c}\mathrm{T}_{2} \\
{ }^{\circ} \mathrm{C}\end{array}$ & $\begin{array}{c}\mathrm{W}_{\text {turb }} \\
\mathrm{kW}\end{array}$ & $\begin{array}{c}\mathrm{E}_{\text {el }} \\
\mathrm{kWe}\end{array}$ & $\begin{array}{c}\mathrm{Is}_{\text {eff }} \\
\%\end{array}$ & $\begin{array}{c}\mathrm{Gen}_{\text {eff }} \\
\%\end{array}$ \\
\hline BT-4 & 0.83 & 8.5 & 2.5 & 280 & 215 & 95 & 78 & $44 \%$ & $82 \%$ \\
BT-4 & 1.66 & 8.5 & 2.5 & 280 & 213 & 198 & 175 & $45 \%$ & $89 \%$ \\
SST-060 & 1.18 & 8.5 & 1.5 & 300 & 220 & 170 & 135 & $39 \%$ & $79 \%$ \\
SST-060 & 3 & 8.5 & 1.5 & 300 & 193 & 591 & 544 & $53 \%$ & $92 \%$ \\
Condensing & 3 & 8.5 & 0.1 & 300 & 50 & 1389 & 1320 & $59 \%$ & $95 \%$ \\
\hline
\end{tabular}

Table 2 